\title{
Sprache und Antisemitismus im 19. Jahrhundert
}

Das abzuhandelnde Thema steht innerhalb des Denkrahmens dieser Tagung an eigentümlicher Stelle. Blickt man auf den Untertitel: "Sprachgeschichtliche Wurzeln des heutigen Deutsch", so muß man sagen, daß antisemitischer Sprachgebrauch jetzt an den Rand der Gesellschaft gedrängt ist. Es hängt dies nicht so sehr mit Selbstreinigungsleistungen der Deutschen zusammen, sondern erstens mit dem Bruch, den die Niederwerfung Deutschlands 1945 brachte, zweitens aber mit der Tatsache, daß die Menschen, denen man mit jenem Sprachgebrauch entgegentrat, aus dem Lande gejagt oder umgebracht worden sind.

Das Thema rückt aber sofort in zentrale Position, wenn man auf den Haupttitel der Tagung schaut: „Das 19. Jahrhundert”. Da hat man ein weites Feld vor sich mit dramatischen Entwicklungen, an denen alle gesellschaftlichen Gruppen Anteil hatten: zu Anfang des Jahrhunderts (in Preußen z.B 1812) die staatsrechtliche Aufnahme der Juden. Sie waren eine kleine Minderheit, die der Mehrheitskultur weithin als das Fremde par excellence erschien, so weit entfernt, daß man diese jüdische Gruppe ein „Stück übriggebliebenes Mittelalter" genannt hat. Kraß geschieden war man insbesondere durch Glauben, staatsrechtlichen, sozialen und ökonomischen Status - nur $10 \%$ der Juden lebten damals in wirtschaftlich gesicherten, wohlhabenden Verhältnissen, $15 \%$ in kleinbürgerlichem Milieu, während das Gros (75 \%) an den Rand der Gesellschaft gedrängt war und dort eine ökonomisch marginale Existenz führte ${ }^{1}$ - weiterhin geschieden von der Mehrheit durch ein besonderes Namensystem, durch spezifischen äußeren Aufzug und getrennt nicht zuletzt durch eine besondere Sprache. Zieht man eine kleine bereits assimilierte Oberschicht $a b$, so kann man sagen: Die zu assimilierende Minderheit sprach durchweg Jiddisch.

Im Verlauf des 19. Jahrhunderts sieht man nun eine dramatische Entwicklung, einen durchgreifenden Abbau der Verschiedenheiten, auch der sprachlichen: gleich zu Beginn die Annahme fester Familiennamen, bald die Assimilierung in Kleidung und Barttracht, sehr schnell die Einfädelung ins zeitalterbestimmende Wirtschaftssystem dergestalt, daß die Juden bis zur Reichsgründung 1870 ihre wirtschaftliche Position fast umdrehen konnten. $Z$ wei Drittel gehörten jetzt zum großen und mittleren,

1 Zu den Sozialdaten vgl. Holeczek 1981, S. 158f; Zmarzlik 1981, S. 251. 
nur $15 \%$ zum Kleinbürgertum und gerade noch $5 \%$ verharrten in der marginalen Randposition. ${ }^{2}$ Jetzt waren viele geneigt, ihre rituellen Verpflichtungen dem problemlosen geselligen Verkehr zu opfern oder sie doch diskret zu beachten. Kurz: Am Ende des 19. Jahrhunderts standen die Juden da, von außen nur noch für Kenner des Milieus zu identifizieren, fast ununterscheidbar, nicht zuletzt, weil sie das alte Eigenidiom nun gegen das Hochdeutsche getauscht hatten. Bedenkt man diesen (vom Startpunkt aus gesehen) dramatischen Umbruch und rechnet hinzu, daß von der deutschbürtigen Bevölkerung nur $5 \%$, höchstens $15 \%$ zum Bürgertum gehörten, ${ }^{3}$ vergegenwärtigt man sich obendrein, welch dramatische Pressionen, ohne jede soziale Abfederung, die Gesamtbevölkerung bei der Geburt der modernen Wirtschaftsformen hatte über sich ergehen lassen müssen, dann ist klar, welch günstiges Feld das 19. Jhdt für die gängigen Zugschemata der Sündenbocksuche gewesen ist. Und der daraus resultierende Antisemitismus brauchte nicht viel Einfallsreichtum, um auch auf sprachlichem Gebiet polemische Feldzüge gegen die Juden zu führen. Ich nenne vier Attacken, die ich einzeln abhandeln werde die erste ausführlich, die folgenden als knappe Skizzen und Forschungsvorschläge.

Erstens: die Attacken auf die besondere Sprache der Juden - auf das Jiddische, als es noch tatsächlich von den meisten gesprochen wurde, und später auf das Jüdeln, nachdem die Vollform des Jiddischen abgelegt war und man nur noch an leichten Abweichungen einen polemischen Ansatzpunkt finden konnte bis hin zu der Zeit, als man - angesichts vollkommener sprachlicher Assimilation - die gar nicht vorhandene Abweichung einfach unterstellte.

Zweitens: an diesem Punkt konnte nun die Argumentationsweise auch umkippen, indem die Antisemiten, aller Beweise für das Kleben der Juden am unmodern-archaisch-minderwertigen Jiddisch beraubt, nun das genaue Gegenteil attackierten: die vorauseilende, zersetzende Modernität präge die Sprache der Juden und unterminiere das gute deutsche Deutsch - in der Presse, im Feuilleton und in seichter, undeutscher eben nur artistischer Literatur. (Dieser Punkt wird aus darstellungstechnischen Gründen hinter dem folgenden abgehandelt).

Dritte polemische Ebene: die antisemitische Markierung der 1812 gewählten Namen - dies, wenn sie markierbare Züge an sich hatten, und wenn nicht, dann die Unterstellung von Namen als die eigentlich

\footnotetext{
2 Vgl. Anm. 1.

${ }^{3}$ Vgl. Kocka 1988, S. 13.
} 
zukömmlichen, an denen dann Spott und Aggression wirklich Haftfläche finden konnten.

Viertes Feld: die Formierung einer spezifisch antisemitischen Sprache und Rhetorik, in der vor allem die biologischen Metaphernsysteme hervorstechen.

Ehe ich nun diese vier Felder ${ }^{4}$ einzeln beschreibe, muß ich noch deutlich sagen, was eingangs nur angedeutet ist: Für mein Thema endet das 19. Jahrhundert 1945. Denn bei der Sprache des Antisemitismus ist es besonders deutlich zu sehen: Die Schauderzeiten des Nationalsozialismus sind nicht plötzlich über die Deutschen hereingebrochen. Die Wurzeln sind im 19. Jhdt klar zu sehen, auch schon ihr Aufwuchern, und ohne das kann man die Zeiten fast völliger Dominanz nationalsozialistischer Sprach- und Reaktionsformen nicht richtig einschätzen. Um die besonders enge Verquickung hier anzudeuten, werde ich auch einige Quellen aus den Anfangszeiten des Nationalsozialismus mit heranziehen.

\section{Angriffe auf die Sprache der Juden}

Es ist unbestritten: Die Aufnahme der Juden in die europäischen Staaten am Anfang des 19. Jhdts war nicht die Folge einer Assimilation, sondern es war ein Vorgriff auf erhoffte und geforderte Angleichung. Dieser den Juden angesonnene "Assimiliationspakt" entsprang einer Mentalität, die nicht weit genug entfernt gedacht werden kann von heutzutage dominierenden Vorstellungen über „interkulturelle Pädagogik”. Gesa Siebert-Ott resümiert in ihrem Aufsatz über ${ }_{n}$ Kulturverlust - Sprachverlust - Identitätsverlust", daß in der Ausländerpolitik ninzwischen ein weitgehender Konsens besteht, emanzipatorischen den Vorzug vor assimilatorischen Konzepten zu geben". 5 Damals konnte Andersartigkeit bei der Mehrheit nur den Wunsch nach alsbaldiger Auslöschung hervorrufen. Die Andersartigkeit der Eintreffenden war deutlich, ja kraß - ablesbar besonders an ihrem sprachlichen Vermögen, das nun so geschildert werden soll, daß die Ansatzpunkte judenfeindlicher Argumentationen auf Anhieb hervortreten. Als Muttersprache, als Sprache des täglichen binnenjüdischen und familiären Verkehrs sprachen sie Jiddisch. Zwar geteilt in west- und ostjiddische Varianten, hatte diese Sprache aber doch eine uns kaum noch vorstellbare Reichweite. Von der Maas bis eben nicht nur an die Memel, sondern über Litauen, Lettland bis zum Peipussee in Estland und in

4 Aus Platzgründen kann ich auf den Vorwurf, den Juden habe man das Rotwelsche, die Gaunersprache, zu danken, nicht eingehen.

5 Siebert-Ott 1990, S. 434. 
Südeuropa noch einmal tausend Kilometer weiter nach Osten - über die Bukowina, die Ukraine bis hin zum Ende des Asowschen Meers konnten sich die Juden verständigen. ${ }^{6}$ Hebräisch, sehr oft nur den Männern bekannt, war im schriftlichen Gebrauch bevorzugt und sonst eine sakrale Sprache, dem Gottesdienst, dem Bibel- und Talmudstudium reserviert. Die oft viersprachigen Ostjuden konnten überdies Russisch und/oder Polnisch. ${ }^{7}$ Eine solche weit in den Osten reichende Sprachmächtigkeit konnte der aufnehmenden Mehrheitskultur nicht unbedingt anheimelnd sein, war doch nicht für die nötige Distanz ausgerechnet zum Osten gesorgt, der seit der Aufklärung als Bezirk tiefster Unkultur eingeschätzt wurde.

Die Aufklärung hatte aber auch das Westjiddische als den europäischen Sprachen unebenbürtige, unkultivierte Sprache gebrandmarkt, zum bloßen „Jargon" erklärt, zum Kennzeichen einer auf niedrigstem Niveau lebenden Bevölkerungsgruppe, unwürdig für einen auf der Höhe der Zeit stehenden Geist. ${ }^{8}$ In diesem Punkt waren sich christliche Beurteiler und Exponenten der jüdischen Aufklärung einig. Goethes Bemerkung über die Sprache im Frankfurter Ghetto ist bekannt:

Die Enge, der Schmutz, das Gewimmel, der Akzent einer unerfreulichen Sprache, alles zusammen machte den unangenehmsten Eindruck, wenn man auch nur am Tore vorbeigehend hineinsah. ${ }^{9}$

Die Einlassungen Moses Mendelssohns findet man nicht weniger oft zitiert: Um einen Rat angegangen für die Neuformulierung des Judeneides vor Gericht, hatte er energisch gegen eine neuerliche Mischung von Jüdisch-Deutsch (=Jiddisch), Hochdeutsch und Hebräisch plädiert.

Ich fürchte, dieser Jargon hat nicht wenig zur Unsittlichkeit des gemeinen Mannes beigetragen; und verspreche mir sehr gute Wirkung von dem unter meinen Bürgern seit einiger Zeit aufkommenden Gebrauch der reinen deutschen Mundart. ${ }^{10}$

„Nur keine Vermischung der Sprachen!"11 Das war der Kulminationspunkt seiner Argumentation und ist für uns ein Hinweis auf die ideolo-

6 Karten vgl. z.B. bei Althaus 1965/68, S. 18; Weissberg 1988, S. 80 f.

7 Information nach Althaus 1965, S. 21.

8 Vgl. z.B. Althaus 1965/68 Teil 2, S. 21 oder ders. 1968, S. 244.

9 Werke Bd 9, S. 149.

10 Zitiert bei Gilmann 1980, S. 516 .

11 Zitiert bei Toury 1982, S. 77. 
gische Basis, die jüdische Reformer und antijüdische Nationalisten gemeinsam betraten, wenn auch zu verschiedenen $Z$ wecken. Jiddisch ist eine sogenannte "Schmelz-"12 oder "Mischsprache"13 - wie das Englische können wir von linguistischer Warte völlig zu Recht sagen, machen aber damit dennoch historisch einen Fehler. Wie wenig diese Mischqualität nämlich dem Englischen etwas anhaben konnte, so negativ schätzten Aufklärer und noch negativer später die antisemitischen Nationalisten diese Tatsache beim Jiddischen ein. Ihm hielt man das "reine" Hochdeutsch als allein würdiges $M a B$ entgegen, und dann stand es da als verunreinigte Sprache. Die Urteile in diese Richtung sind Legion: "verdorben und verzerrt" sagte Goethe, ${ }^{14}$ "halb tierische Sprache" 15 meinte der jüdische Historiker Graetz, „abgestoßendes Gestammel" urteilten wiederum andere. ${ }^{16}$

Jetzt deutet sich ein wichtiges Strukturmerkmal des sprachgeleiteten Antisemitismus an. Die bestimmte Eigenart des Jiddischen kontrastiert in besonders scharfer Weise mit den Zielpunkten und ideologischen Positionen der romantisch-national Denkenden: Ein Gemisch (bekanntlich aus vorwiegend deutschen, aber auch hebräischen und slavischen Bestandteilen) war diese Sprache und konnte so nur der Verachtung anheimfallen in einer historischen Konstellation, in der Kampf um Einheit, Zurückdrängung der Dialekte, Errichtung einer verpflichtenden Sprachnorm selber ein Entwicklungsziel der deutschen Nation war, das man seit Ende des Jhdts sogar mit chauvinistischen Reinheitsgeboten durchsetzen wollte. ${ }^{17}$ Eine noch selbst um Existenz, Festigkeit und Identität

12 Terminus bei Kiefer 1985, S. 1201.

13 Althaus 1965, S. 7.

14 Zitiert bei Althaus 1968, S. 241.

15

16 Zitiert bei Aschheim 1982, S. 12. Von Hundt-Radowsky (1819, S. 67) behauptet ausdrücklich eine Änlichkeit zwischen der Sprache der Juden und der Zigeuner. Richard Wagner beklagte später, daß in diesem Jargon mit wunderlicher Ausdruckslosigkeit Worte und Konstruktionen durch einander geworfen werden" (1850, S. 78).

Vgl. Bernsmeier 1980, S. 118ff. Die antisemitischen "Alldeutschen Blätter" geißelten Fremdwortgebrauch mit Verdikten wie: ,Hochverrat am teuersten Erbe der Ahnen" (4, 1894, S. 127) oder mit Aufforderungen solcherart: "Auch heute sollte der schlichte in seinem sprachlichen Gefühl noch nicht geschädigte Mann nicht anders denn unsere Ahnen sprechen" (ebd. S. 84). 1898 plädierten sie dann für ein "Sprachengesetz für das Deutsche Reich" (S. 149f.), das scharf gegen Anderssprachige in Elsaß-Lothringen und in den polnischen Gebieten Front machen sollte. Einen besonders guten Blick 
gegen Kleinstaaterei kämpfende Nation muß im 19. Jhdt. immer als Hintergrund gedacht werden. „Was Deutsch spricht soll Deutsch werden" hatte es ja in der Paulskirche geheißen. ${ }^{18}$ Schließlich rücken wir noch das Charakteristikum deutschen Bürgertums vor unser Auge, das ja nicht auf politische Macht zu setzen in der Lage war und daher mit geistiger, mit Bildungsmacht zu kompensieren suchte. Vor diese Horizonte gestellt, konnte sich das Jiddische immer nur als ausgesprochen defizitär, den deutschen Interessen zuwiderlaufend abheben. Bedenkt man nun noch die besondere Funktion, die die deutsche Sprache innerhalb dieser Einheitswünsche hatte, am konzentriertesten vielleicht ausgedrückt von Jakob und Wilhelm Grimm in der Vorrede zu ihrem Wörterbuch: "Was haben wir denn gemeinsames als unsere Sprache und Literatur?"19, dann sehen wir die großen Linien, die genaue Vorwegeinschätzungen über die Verdammung des Jiddischen und ihre Gründe ermöglichen.

Gegen dies allgemeine Panorama gehalten, wiegen spezifische, aus den Strukturmerkmalen des Jiddischen entwickelte, pur grammatische Argumentationen nicht so schwer. Es paßte zwar genau in einen fatalen Vorurteilszusammenhang und konnte auch sicher innerhalb der wissenschaftlichen Welt, nicht aber in der communis opinio Niederschlag finden. Das Jiddische hat nämlich eine stark reduzierte Flexion. Im SingularParadigma der Nomen verfügt es lediglich über zwei Formen, im Plural nur noch über eine; statt des Genitivs wird durchweg die periphrasti-

auf die Gesamtentwicklung bietet: Frank 1976 - von Herders Emphase für "Reinheit" der deutschen Sprache (Bd. 1, S. 403) über die Funktion der Spracherziehung während der napoleonischen Freiheitskriege ( nötig, in allen Deutschen die Liebe zur Muttersprache zu wecken und ihnen die Pflege und Reinerhaltung des Mutterlautes zur heiligen Pflicht zu machen", Bd. 1, S. 439) bis zu dem nationalen Schub nach der Reichsgründung, der die Einheitssehnsucht bis zum "Germanismus" (Otto Lyon) steigerte und mit Tönen folgender Art grundierte: Es bleibe doch die Muttersprache ,der stärkste und dauerhafteste Kitt der Nationalität, das festeste und wesentlichste Band des Volksthums, das alle umschlingt, die in einer Zunge reden, mögen sie auch in den fernsten Gegenden weilen und wohnen" (Bd. 2, S. 487). Standen die Dinge so, dann war es konsequent, daß sich Sprachreiniger wie H.K. Lenz (1895) aufmachten und ,Jüdische Eindringlinge im Wörter- und Zitatenschatz der deutschen Sprache" zwecks Ausmerzung zusammenstellten.

Mosse 1970, S. 10.

19 Deutsches Wörterbuch Bd. 1, Leipzig 1854, Sp. III. Zwar hatte „Sprache als einheitsstiftendes Symbol" (Gessinger 1980, S. 149) im zerrissenen Deutschland eine besondere Funktion. Die allgemeine Durchschlagskraft solcherart Argumentationen kann man aber erst richtig ermessen, wenn n: an sie nicht mehr allein als deutsches Spezificum sieht. Karl W. Deutsch zählt (1972, S. 600 ) allein 15 europäische Nationen auf, die in 19. Jhdt über ihre Sprache und Literatur zu nationalem Selbstbewußtsein kamen. 
sche Form mit der Proposition 'fun/fin' benutzt. ${ }^{20}$ Generell, sagt Josef Weissberg, habe das Jiddische "die optimale Vereinheitlichung" angestrebt. $^{21}$ Diese Fakten muß man sich konfrontiert denken mit dem einhelligen Urteil führender Sprachwissenschaftler des 19. Jahrhunderts. Wilhelm Wackernagel, Friedrich Schlegel und vor allem Wilhelm von Humboldt interpretierten doch mindere Flexion und erhöhte Analytizität (im Denkraum von norganisch" vs. "mechanisch") als Anzeichen von minderem Rang der Sprache. ${ }^{22}$ Damit nun aber nicht der Eindruck entsteht, einzig und allein in deren Studierstuben und elitären Gesprächszirkeln seien solche Meinungen vertreten worden, sei hier schon der später ausführlich zu Wort kommende Hamburger Pädagoge Anton Rée zitiert, der seine Glaubensgenossen unbedingt vom konjugationsund deklinationsarmen Jiddisch abbringen wollte, glaubte er doch als treuer Gefolgsmann jener großen Vorbilder:

Je ursprünglicher einem Volke seine Sprache ist, desto biegungsreicher ist sie und umgekehrt. [...] Je näher ein Volksstamm dem eigentlichen Kerne der Nation steht, desto biegungsreicher ist sein Dialect und umgekehrt. ${ }^{23}$

Welchen Erfolg man nun mit der Verhöhnung des Jiddischen und seines verwässerten Ablegers, des "Jargons", ${ }^{24}$ haben konnte, kann am besten

20 Vgl. Weissberg 1988, S. 126, 127. Über Vereinheitlichungsphänomene beim Verb vgl. S. 135 ("Das Präsens wurde vereinheitlicht"; "Das Präteritum verschwand spurlos"), S. 139 (Einebnung des Unterschiedes $z$ wischen 1. Pers. und der durch Grimmsche Brechung geeinten 2. +3 . Person).

21 Ebd. S. 139. Vereinfacht wurde auch die Behandlung des deutschen Verbkomplexes, der ja im Deutschen durch die Satzklammer auseinandergerissen ist, in der Tiefenstruktur aber, zusammengefügt, als eine Konstituente angesetzt wird und so auch im Jiddischen und im Jargon an der Oberfläche erscheint, also eigentlich viel "richtiger" erscheint (was Wagner noch beckmesserisch als undeutschen Fehler brandmarkte, Werke Bd. VIII, S. 231). Zur Behandlung der Wortfolge in Hauptsatz, Nebensatz (identisch!) und bei zusammengesetzten Prädikaten vgl. z.B. Birnbaum 1974, S. 42; Kiefer 1985 , S. 1209 , der Grad seiner Trennung von unflektierten Elementen [...] bleibt minimal ${ }^{n}$ ) und das Urteil von Althaus 1981, S. 219: "Aufhebung der Klammerstellung des Verbs am Satzende der Nebensätze [...] gilt als typisch für die jüdische Syntax und wird darum bei literarischem Gebrauch als wichtigstes syntaktisches Mittel angewendet".

22 Vgl. hierzu Römer 1985, S. 105-110. Dort auch Urteile über die (etwas weniger stark herausgestrichene) Minderwertigkeit des Hebräischen.

23 Rée 1844, S. 73.

24 Die Verwechslung der beiden bekämpfte schon Nathan Birnbaum 1910, S. $315 f$., der, wie später viele, klarstellte, daß das Jiddische eine selbständige Sprache und der "Jargon" (das "Jüdeln", "Mauscheln") eben nur die Verwässerung des ersten durch Mischung mit Assimilationsdeutsch sei. 
an der judenfeindlichen Posse "Unser Verkehr" gezeigt werden. Ein bis dahin unbekannter Schreiber, der Breslauer Arzt Karl Borromäus Sessa, hatte sie 1812 verfaßt und 1813 in seiner Heimatstadt zur Aufführung gebracht. Als sie nun 1815 auch in Berlin gegeben werden sollte, wurde sie, kurz bevor sich der Vorhang hob, vom judenfreundlichen Staatskanzler Hardenberg höchstpersönlich verboten. Den Effekt der dann schließlich doch durchgesetzten Aufführungen schildert Hans-Joachim Neubauer anhand zeitgenössischer Quellen so:

Der Erfolg von „Unser Verkehr” war überwältigend: 'bis zu den untersten Volksklassen' wirkte seine Anziehungskraft, und selbst 'Menschen, die man darüber erhaben glauben sollte', zogen ins Theater und bescherten den Königlichen Schauspielen volle Kassen. ${ }^{25}$

Wie ist das bei der folgenden Trivialhandlung möglich? Der jüdische Trödelhändler Abraham Hirsch und seine Frau Rachel verabschieden ihren Sohn Jakob, der in der Welt sein Glück machen soll. Dieser trifft auf Lydie, Tochter des reichen Juden Polckwitzer. Um die Schöne bewirbt sich - zunächst mit größerem Erfolg - auch Isidorus Morgenländer, ein deutschtümelnder, überassimilierter Stutzer. Als das Gerücht aufkommt, Jakob habe das große Los gezogen, schwenkt Lydie auf Jakob um. Als sich das Gerücht als Gerücht erweist, läßt sie, wie alle, sofort wieder von ihm ab.

Der Witz liegt in folgendem: Vater Abraham Moses spricht so (hier bei der Verabschiedung des Sohns):

As der Sühn süll raisen ebbes Moos verdienen - nü, so wollen mer wünschen glückliche Geschäfte uf den Weg! - Er süll finden blanke Tholer un' Lugedore, er süll sich in Acht nehmen fer falschen Pepieren und schofler Woore! (S. 5)

Der Sohn Jakob spricht so:

Ich will werfen den Jüden bei Seit, ich bin doch aufgeklärt - ich hob doch gar nischt Jüdisches an mer! (S. 8f.)

Jeder hört: Er spricht anders als der Vater - etwas anders, wenngleich noch nicht so wie die angebetete Lydie Polckwitzer, die sich so vernehmen läßt, als ihr der ungeschickt hastige Jakob ein Loch in die Schleppe getreten hat:

Däs Kleid schenk' ich weg, darauf kommt mir's nicht an - aber, der Anstand! - Mer seht's doch nicht, Lieber? (S. 9)

25 Neubauer 1987, S. 318. Über die Auführungsgeschichte S. 314-316. Über die Breitenwirkung des Stücks vgl. auch Bering 1988, S. 233. 
Hier stimmt schon die Wortstellung, nur Reste jiddischer Lautung bleiben. Richtiges Deutsch spricht keiner, denn Isidorus Morgenländer, der es in seinen Kenntnissen am weitesten gebracht hat, läßt sich bei seinem ersten Zusammentreffen mit seinem Konkurrenten Jakob auf höchst eingentümliche Art vernehmen:

JAKOB (erblickt ihn und läuft hastig auf ihn zu). Isaschar! Isaschar! Bist du's? Wo kumst du zu gaihn her?

ISIDORUS (immer ernst, monoton und voll Pathos). Isidorus heiB ich jetzt und komme aus den Fernen des geheimnißvollen Osten! - Hier aber erblicke ich wie im Traum eine alte, wohlbekannte Gestalt, und eine freundliche Stimme ruft mich bei meinem verklungenen Namen. (S. 17)

Man sieht: Die Register reichen von ganz „unten", vom tiefsten Jargon, der den Zuschauern natürlich als reines Jiddisch vorkommen sollte, bis zur Travestie eines Hochglanz-Hochdeutsch. Jede Figur bekommt auf dieser Skala eine bestimmte Stelle zugewiesen. Hans-Joachim Neubauer, Mitarbeiter am "Zentrum für Antisemitismusforschung”, hat das sehr gut beschrieben. ${ }^{26}$ Der Effekt besteht im witzig entlarvenden Kontrast: beim alten Abraham im Gegeneinander von fast ungebrochenem (wenngleich für die Zuschauer zurechtgemodelten) „Jiddisch" als unsägliche, nie und nimmer zu korrigierende Abweichung vom echten, würdigen Deutsch. Bei Jakob besteht sie im versuchten Abschliff des jargonhaften Jiddisch; es ist zuweilen von den ganz groben phonologischgrammatischen $A b w e i c h u n g e n$, vom Hebräischen völlig gereinigt und verweist jetzt hämisch auf den Kontrast von angezielter, aber faktisch eben nicht erreichter Annäherung. Bei Lydie ist der Abstand schon deutlich kleiner; sie „jüdelt" nur noch, und bei Isidorus Morgenländer schließlich amüsiert der Kontrast von grammatisch richtigem Deutsch und jenem stilistischen Obersoll, das die richtige Art, Deutsch zu reden auf noch lächerlichere Weise verfehlt. Denn: Oberhalb getroffen ist auch daneben. Bezeichnend, weil die Kernaussage symbolisierend, ist die Reaktion von Abraham, Rachel, Polckwitzer, Lydie und Jakob als der Irrtum vom großen Geld auffliegt: Durch diesen Schock der Kontrolle beraubt, beginnen alle fünf ihre Schmerzensausrufe mit $A i$ waih! - geschrieben mit vom deutschen orthographischen System abweichenden ai. (S. 32) Durch dies sprachliche Signal sind sie - trotz aller ihrer angedrechselten Unterschiede - auf die eine Ebene zurückgestellt: unassimilierte (und viele haben gedacht: unassimilierbare) Juden. Keiner machte sich sicher Gedanken darüber, daß mit der ai-Schreibung die phonetische Eigenart

26 1988, S. 35-42. Für die Überlassung dieser unveröffentlichten Magisterarbeit danke ich dem Verfasser. Er bereitet eine Dissertation über den Antisemitismus auf deutschen Bühnen in der ersten Hälfte des 19. Jhdts vor. 
des deutschen Diphtongs [aj] ja sogar viel richtiger getroffen war als mit der vorschriftsmäßigen, phonetisch eindeutig „falschen" Verschriftung $e i$.

Das Vorgetragene kann man nun in einer Mikroanalyse der grammatischen und stilistischen Eigentümlichkeiten detaillierter beschreiben. Es würde Präziseres, in der Substanz aber nichts anderes herauskommen. Wichtiger für uns ist eine weitere Überlegung, warum die Verhöhnung des jüdischen Idioms im ganzen 19. Jhdt solch durchdringende Kraft hatte. Niemand kommt umhin, fremdsprachigen Ankömmlingen Defizite in der Zielsprache, aber gleichzeitig sicheren Besitz einer Erstsprache zu attestieren. Eben diese Erstsprache hatten die deutschen (westjiddischen) Juden nicht. Sie waren mangels einer anderen Primärsprache in toto eine Abfälschung des Deutschen, ohne Rückzugs- und Stabilisierungsmöglichkeit in einer Primärsprache und daher falsch und lächerlich bis in den Grund.

Bekanntlich haben sich die Juden willig auf den Weg der Assimilation gemacht. In der letzten Zeit mehren sich die Warnungen, sich die Geschwindigkeit des Vorrückens zu groß vorzustellen. ${ }^{27}$ Die moderne Linguistik, verstanden als ein Teilbereich der kognitiven Psychologie, hat überzeugende Argumente zusammengetragen, daß man eingeschliffene Sprachstrukturen nach der Pubertät restfrei so leicht nicht abwerfen kann, weil bis zu diesem Zeitpunkt genetisch vorgegebene Raster eingefahren werden, die dann aber als fixiert gelten müssen. So ist wohl dem Hamburger Pädagogen Anton Rée zu glauben, der 1844 in einer theoretisch außergewöhnlich hochstehenden Abhandlung über „Die Sprachverhältnisse der heutigen Juden” schreibt, daß „die überwiegende Mehrzahl der Juden noch heutigen Tags" Reduktionsformen der alten Mundart sprächen und nur ${ }_{n}$ sehr wenige" ununterscheidbar reines Deutsch. ${ }^{28}$

27 Vgl. z.B. die jüngsten besonders abgewogenen Äußerungen von Volkov (1990). Lowenstein (1976) stellt die Positionen so gegeneinander: a) „Most writers describe the changes in Jewish life as if they were rapid and relatively uniform. [...] Yiddish disappeared in Germany soon after Mendelssohn's translation of the Bible" (S. 41) (für diese Position vgl. z.B. das besonders krasse Fehlurteil von Best (1973, S. 39): Westjiddisch - ein Sprachzweig, nder im 18. Jahrhundert bis auf geringe Reste unterging") - „In the early nineteenth century the German Jews who had abandoned or substantially modified their traditional way of life were still in the minority" (S. 42).

28 Rée 1844, S. 92 . Die hier nur für die deutschen Verhältnisse vorgetragenen Fakten weitet Ree sofort zu einem allen Juden eigentümlichen Problem aus: nso stellt es sich sehr bald entschieden heraus, daß viele Juden ihre Muttersprache nicht nur im nördlichen, sondern auch imı südlichen Deutschland, nicht nur in genanntem Lande, sondern in ganz Europa, ja, auf der ganzen Erdoberfläche, [...] auf eine eigenthümliche Weise sprechen, so daß sich das jüdische Element, die jüdische Mundart [...] nicht verkennen läßt." (S. 93) Man kann also sehr wohl die jüdische Geschichte unter dem Aspekt eines 
Unser Thema "Sprache und Antisemitismus" drängt jetzt natürlich zur Frage, wie diese sprachlichen Eigentümlichkeiten denn im Alltag aufgenommen worden sind, denn: Die Lachnummer Sessas muß ja nicht unbedingt die soziale Wirklichkeit verzerrungsfrei widerspiegeln, wenngleich ein solcher Erfolg „bis zu den untersten Volksklassen" (s.o. S. 332) nicht ohne jeden gelungenen Verweis auf die Realität erklärbar ist. Der Pädagoge Rée hingegen spricht die Realität direkt an:

Jede auch nur entfernte Berührung eines durch den in Rede stehenden Dialect sich Auszeichnenden mit einem Fremden zieht ihm Gespött und Verhöhnung zu; mit welchem Recht dies geschieht, ist uns hier wieder gleichgültig; [...] Batterien stürmen, Horatius Cocles Il. sein, das ist nur eine Kleinigkeit gegen den Heroismus, welcher gerade bei klarer Einsicht und einem liebevollen Herzen dazu gehört, ein durch die Sitte scheinbar privilegiertes Lachen geduldig hinzunehmen. [...] Eine spottende Miene des Christen! und der Jude, selbst der beste und sanfteste, wird Meilen weit von dem Herzen jenes entfernt. (S. 40f.)

Ganz auf Assimilationskurs, plädierte Rée für intensive Bekämpfung der jüdischen Mundart ${ }^{29}$, und man kann davon ausgehen, daß seit der Mitte des 19. Jhdts die Menge der akzentfrei sprechenden Juden deutlich zugenommen hat. Ab 1870 waren sie die deutliche Mehrheit. In der vierten Generation dann - um 1900 - muß man mit einer vollkommenen Sprachassimilation für die in Deutschland geborenen Juden rechnen.

besonders gelagerten Zweitsprachen-Erwerbs sehen und diesen dann unter Herbert A. Strauss umfassenden Begriff von der jüdischen "Akkulturation" stellen: "Akkulturation kann an objektiven, d.h. durch unabhängige Beobachter nachprüfbaren Merkmalen, wie Sprache, Gewohnheiten und Kleidung im einzelnen festgestellt werden." (Strauss 1985, S. 9). Ausführlich über Rée s. Freimark 1980, S. 250f. mit Ausführungen über die parallel verlaufende Debatte über die Zurückdrängung des Plattendeutschen.

Rée 1844, 60f. Sehr interessant ist an dieser Stelle, daß Rée zwar die mangelnde Gleichberechtigung als Bürger der verschiedenen Länder bedauert, aber dagegensetzt, daß die Juden aber so gut wie diese gleich berechtigte Deutsche" seien (S. 58). Dementsprechend fiel das Deutsch der Juden besonders pur aus, weil sie ja den zugrundeliegenden (jiddischen) Dialekt vollkommen verbannen wollten/mußten, während die "Deutschen" ihre dialektale Herkunft nicht so stark abzulegen gezwungen waren, sondern durchaus auch durchscheinen ließen. So ist es zu verstehen, wenn Toury $(1982$, S. 84) sagt: Sogar die Professoren hätten an den Universitäten jeweils noch berlinert, "Sächsisch" oder "Bayerisch" gesprochen, allein die Juden eben reines Deutsch, welche Bemerkung hier schon die Basis für die im unmittelbaren Anschluß dargestellten Angriffe abgeben und die Möglichkeit vorbereiten soll, zu einer umfassenden Beurteilung des Unrechtsgehalts des sprachlichen Antisemitismus zu kommen. 
Wie wurde nun dieser Fortschritt von den Antisemiten eingeschätzt? Sie beriefen sich immer wieder auf einen wahrlich deutschen Zeugen, auf Richard Wagner, der sich 1850 in seinem Pamphlet: "Das Judenthum in der Musik" so geäußert hatte:

Der Jude spricht die Sprache der Nation, unter welcher er von Geschlecht zu Geschlecht lebt, aber er spricht sie immer als Ausländer. [...] In einer fremden Sprache wahrhaft zu dichten, ist bisher selbst den größten Genies noch unmöglich gewesen.

Besonders widere "uns" an, die rein sinnliche Kundgebung der jüdischen Sprache. Es sei ein "fremdartig und unangenehm", zischender, schrillender, summsender und murksender Lautausdruck", kurzum ein "Gelabber". ${ }^{30}$ Linguistische Scheinargumentation (fremdartig, zischend, schrill) geht ganz offen ins reine Schimpfen über (murksen, Gelabber). Wichtiger noch ist die Apodiktizität des Urteils. Da gibt es keine Beschränkung auf die noch mit jiddischem Einschlag sprechenden Juden und keine Sonderrolle für die steigende Zahl der rein sprechenden. Es trifft alle.

Die von Wagner vertretene Position bot so auch eine Handhabe, wenn die angeführten Sprachkennzeichnungen ganz offenbar nicht mehr zu hören waren. Man konnte in den Mystizismus fliehen: Er spricht das nicht als Deutscher. Ich zitiere hier den antisemitischen Literaturwissenschaftler Otto Hauser, um zu zeigen, daß dieser Argumentationsbogen, in den sich Adolf Bartels ${ }^{31}$ als eine tragende Säule stellte, bis 1933 reicht:

30 Wagner 1850, S. 70 f. Ähnlich über die jüdische Musik, deren Wesen er mit dem der jüdischen Sprache in Verbindung setzt: "Wer ist nicht von der widerwärtigsten Empfindung [sc. der Musik in der Synagoge], gemischt von Grauenhaftigkeit und Lächerlichkeit, ergriffen worden beim Anhören jenes Sinn und Geist verwirrenden Gegurgels, Gejodels und Geplappers, das keine absichtliche Karrikatur widerlicher zu entstellen vermag" (S. 76). Die These, unausweichlich undeutsch sei besonders die Intonation der Juden wurde auch noch in der Weimarer Republik verfochten, z.B. von Stapel (1928, S. 42), vom Rasseforscher Günther z.B. (vgl. Römer 1985, S. 172). Vgl. auch Stapels (1928, S. 42) Klage über die vielen Gutturale und den aggressiven Satzrhythmus der jüdischen Sprache. Schon N. Birnbaum führte das Argument ins Feld, daß jener immer wieder behauptete Mißklang nur in "deutsch gewohnten Ohren" wahrgenommen werde (1910, S. 319).

31 Er bezog sich (1925, S. 37), wie viele andere, auf die gängige Theorie der Mimikry-Natur der Juden, die ja dazu taugte, jedwede sichtbare Manifestation als bloße Mache zu denunzieren, also auch das offensichtlich reine Hochdeutsch. "Daß jüdische Dichtung in deutscher Sprache einen anderen Klang hat als echtdeutsche, wissen ja auch wir Laien [...], ja, wir erkennen auch die jüdisch deutsche Prosa als solche, empfinden z.B. ganz deutlich, wo Ludwig Börne mauschelt, und bestimmte Judaismen im modernen Zeitungsstil" (ebd. S. 42). "Wer aber das deutsche Blut nicht hat, der kann 
Nichts scheidet den Juden - jeden Juden - so scharf von dem arischen Deutschen wie seine völlige Unfähigkeit, das Deutsche deutsch zu sprechen und zu schreiben. ${ }^{32}$

Natürlich bürdet solch extreme gegen den offenen Augenschein gerichtete Position Beschwerlichkeiten, genauer: Uminterpretationsverfahren auf. Es wurden da zwei Wege beschritten. Dem ersten soll sogleich, dem zweiten etwas später nachgegangen werden.

Wenn man es nicht wirklich hören kann, dann muß man die jüdische Sprechweise hinter der äußeren Fassade beleuchten, und dann kommt das Jüdeln plötzlich doch noch heraus. Ich zähle Fälle dieser Art auf und dazu welche, die ähnliche Funktion hatten:

1. Der Schauspielerin Edith Krohn (dieser Fall ist sehr gut bezeugt) gefährdete man 1910 die Karriere, als herauskam, sie sei Jüdin; denn genau von diesem Zeitpunkt an hörten plötzlich viele, daß sie doch tatsächlich nicht rein lautiere, sondern etwas jüdele. ${ }^{33}$

auch nicht vollen Anteil haben an der deutschen Sprache" (Bartels 1915, S. 94); die deutsche Sprache ist und bleibt ihm im Kern eine fremde, soweit er sie auch zu beherrschen scheint". "Sind denn bei Heine wirklich Naturlaute?" (Bartels 1906, S. 95, 231; vgl. dort weiter gegen Heines Sprache, S. 215).

32 1933, S. 16. Das waren nicht nur seltene Blüten aus nationalistischakademischem Milieu. Ignatz Goldziher berichtet z.B. in seinem Tagebuch am 14.8.1894 (1978, S. 179), daß er während seiner Ferien im Tutzinger Schloß folgende Einschätzung der Gräfin Levetzow anhören mußte: $k$ keiner von ihnen [sc. von der njüdischen Rasse"] könne Deutsch, auch Ebers' Schriften werden von Guthe in Leipzig corrigirt, man erkenne am Stil gleich, dass der Verf. Jude ist." Auch Mystizismen der angeführten Art waren nur Ableger viel umfassenderer Denkstukturen: „Der Hammer”, die verbreitetste antisemitische Zeitschrift, hatte schon 1905, S. 272 einen Artikel über die "Stärkung des deutschen Wesens durch die deutsche Schule" mit dem erstaunlichen (aber für Abweisungen sehr leistungsstarken) Satz begonnen: "Es läßt sich nicht leugnen: Der Deutsche von heute hat in seinem Wesen viele undeutsche Eigenschaften angenommen. Man kann denjenigen nicht ganz Unrecht geben, die behaupten, die Mehrzahl der Deutschen sei im Denken, Fühlen und Handeln gar nicht mehr deutsch." Jeder noch so redlichen Selbsteinschätzung der Menschen wie auch den objektiven Fakten konnten durch solch mysteriöse Annahmen der Argumentcharakter genommen werden. 1913 dekretierte z.B. „Der Hammer” über die Ostjuden und das Berliner Kulturleben: „Er selbst [sc. der Ostjude] hat - nach seinen Begriffen - die Hindernisse eines fremden Landes, einer inm oft fremden Sprache überwunden." (S. 299) Daß man für eine solche bloß mysteriöse Annahme an keiner Stelle konkrete Sprachanalysen als Beweisstücke vorlegen konnte, versteht sich von selbst. Alfred Kerr in Anm. 42. 
2. Äußerungen von Juden belegte man in despektierlicher Weise mit jiddischen Ausdrücken: "Geseiere" seien die Argumentationen seiner Gegner, meinte Adolf Bartels.

3. Antisemitische Pamphlete wurden in den 1890er Jahren noch ganz im Jargon geschrieben, ${ }^{34}$

4. die deutsch geschriebenen kräftig mit jiddischen Ausdrücken und Orthographien untermischt. Ein einziger Ausruf Waih! oder haißt (mit ai geschrieben) hatte entlarvende Funktion. ${ }^{35}$

5. In Dramen und Romanen tauchten jüdisch sprechende Personen auf, um zu zeigen, wie die Juden wirklich seien und um darzutun, daß sie eigentlich nicht zu assimilieren seien. ${ }^{36}$

Wo dann schließlich selbst die verfälschende Kraft der Antisemiten nichts mehr Jüdisches hinter der offensichtlich lautreinen Sprache ausmachen konnte, da wurde schließlich „das Sprachproblem [...] zum Problem der Tendenz und des Inhalts": Jetzt wurde "Mauscheln" (d.h. wie Mausche [jidd. = Moses] sprechend) zu einer pseudolinguistischen Katergorie, die in Wirklichkeit nur noch den verderblichen Inhalt der Rede meinen sollte. ${ }^{37}$

Natürlich wurde die Kenntnis des Jiddischen und des jüdelnden Jargons auch wachgehalten durch die kursierenden Witzsammlungen,${ }^{38}$ durch die Sondersprache bestimmter Gewerbetreibender, die Viehhändler z.B., ${ }^{39}$

34 Z.B. StuBlieb 1892.

35 Vgl. z.B. Der Mauscheljude 1880, S. 4, 10, 13, 14, 21 u.ö.

36 Z.B. Althaus 1981, bes. S. 226 über Dinters Machwerk ${ }_{n}$ Die Sünde wider das Blut". Gelber $(1986$, S. 165): „Judendeutsch als ein immer wiederkehrendes wichtiges Element des deutschen literarischen Antisemitismus fungiert hat". Dort auch über die faktisch antisemitische Wirkung des Jiddischen in Gustav Freytags "Soll und Haben" (S. 170, 175).

${ }^{37}$ Abgeleitet bei Toury 1982, S. 92 (dem sicherlich tiefdringendsten Aufsatz zu den angeschnittenen Fragen).

38 Z.B. Jossel 1912 (in der 41. Aufl.!): 190 gepfefferte Jüdische Witze. Weißensee bei Berlin;

39 Vgl. Althaus 1965, S. 1f; Bischoff erklärt die Notwendigkeit seines: nJüdisch-Deutscher Dolmetscher. Ein praktisches Jargon-Wörterbuch [...]" so: "Unentbehrlich" sei die Kenntnis des jüdischen Jargons "für alle die, welche mit dem niederen jüdischen Handelsstande, z.B. mit Viehhändlern, Produkten- und Altwarenhändlern, Hausierern etc. in engerer geschäftlicher Verbindung stehen" (1901, S. 6). Über diese geradezu ritualisierte Händlersprache vgl. auch Toury 1982, S. 87. 
auch durch die neu aus den Ostgebieten Kommenden. ${ }^{40}$ Aber die negative Tradition allein hätte wohl auch genügt, um die antijiddische Polemik so problemlos klappen zu lassen, wie sie z.B. in Goebbels' KrawallZeitung „Der Angriff” tatsächlich gebraucht wird - 1928 z.B.: Korrespondieren könne man mit dem Berliner Polizeipräsidium nur in Jiddisch, weil man allein diese Sprache dort verstehe; ${ }^{41}$ Alfred Kerr sei der "grauße" Literaturpapst von Mosse. ${ }^{42}$ Mit dem Ruf "neudaitsch alle Wege" biedere sich der Parteiführer Marauhn beim Reichsbanner an und habe prompt die "Daitsche Staatspartei"43 gegründet - dies alles garniert mit immer wieder auftauchendem Waih!, z.B.:

Lenchen Mayer mit dem weichen ay, fiel in Ungnad' bei Herrn Böß. Au waih! ${ }^{44}$

Oder man legte das, was man für Jiddisch hielt, den verhaßten Personen auch direkt in den Mund, Leopold Jessner z.B., dem Berliner Regisseur, der durchgreifend modernisierte und nicht in den staubüberdeckten Requisiten und im Interpretationsmief des Wilheminischen Prunktheaters verkommen wollte; ihn traktierte man deshalb in der Theaterkritik des "Angriff" so:

Wer sagt, daß Schiller, Goethe und Shakespeare es gemeint haben e so? Kennte mer nicht behapten, daß se gemeint haben eppes anderes? -

40 Seit dem Berliner Antisemitismusstreit war Treitschkes Diktum vom "hosenverkaufenden Ostjuden" gängig, der sich alsbald durch dunkle Geschäfte nach oben durchgeschlängelt habe, um die Schaltstellen der deutschen Wirtschaft zu besetzten. Über deren „häßliche und lächerliche Sprache, über ihre Tracht und was sonst noch der Bespöttelung und Entrüstung wert scheint", vgl. die umfassende Arbeit von Maurer (1986, hier S. 29).

41 Angriff 1928, Nr. 49, S. 5.

42 Angr. 1929, Nr. 22, S. 2, wo der so Angegangene übrigens noch besonders verhöhnt wird, weil er doch tatsächlich das Jiddische mit dem (übrigens völlig richtigen) Argument verteidige, daß es naltes gutes Sprachgut des früheren Mittelalters" sei, welcher Rückbezug wohl nur etwas Richtiges treffe, wenn man bedenke, daß "das "Deutsch" des Herrn Kerr in gewisse infantile Bezirke sprachlicher Unvollkommenheiten zurückweist".

43 Angr. 1930, Nr. 61, S. 1; vgl. auch „Daitsche Staatsbirger jiddischen Glaubens" Angr. 1930, Nr. 62, S. 9.

44 Angr. 1929, Nr. 24, S. 13 (es handelt sich um die jüdische Fechterin und den Berliner Oberbürgermeister); vgl. auch die Redeweise eines Wucherjuden in Angr. 1930, Nr. 72, S. 9: " Se nehmen m'r nur mai Zait!" (über die eigentlich lautgerechtere Verschriftung vgl. o. S. 333f.); für den abundativen Einsatz des Signals Waih sei aus dem "Angriff” angeführt: 1927, Nr. 1, S. 3; 1928, Nr. 24, S. 5; Nr. 23, S. 5; 39, S. 3; 42, S. 3; 1929, Nr. 35, S. 6 und 12; 1930, Nr. 52, S. 2 und öfter. 
Und Reb Ephraim Leopold Jeßner Jeiteles stellte fest, daß die Klassiker auch gemeint haben kennten eppes andres. ${ }^{45}$

Jedermann vestand, was jeweils gemeint war, und dieses (ohne viele besondere Worte funktionierende) polemische Mittel dankte seine Treffsicherheit eben auch der langen Tradition antisemitischer Verfemung des Jiddischen im 19. Jhdt.

Ich bin in dieser breiteren Darstellung des Antisemitismus gegen Jiddisches so verfahren, daß die drei anderen angekündigten Punkte kurz abgehandelt werden können. Es ist jetzt nämlich ein Panorama entwickelt, in dem diese drei problemlos verortet werden können. Überdies sind uns jetzt Verfahren bekannt, die es ermöglichen, über die wirklichen Bestimmungspunkte jüdischer Existenz (reines Hochdeutsch seit zirka 1870, spätestens 1900; schon vorher durchweg deutsch[national]e Einstellung) hinwegzuspringen und Juden sich auf einer imaginierten Ebene so zurechtzumodeln, wie es die antisemitische Ideologie erforderte, jüdelnd nämlich.

\section{Namenpolemik}

Als zweite Ebene sprachorientierter Attacken nun die antisemitische Namenverfemung.

Wie war Jakob in jenem Erfolgsstück "Unser Verkehr" auf seinen alten Bekannten und Konkurrenten Isidorus Morgenländer zugegangen? - mit dem Namen "Isaschar". Der so Angesprochene hatte dann eine Namenänderung signalisiert. „Isidorus heiße ich jetzt." Sessa stellt diesen Wechsel nicht dar als eingeräumtes Recht, ja als eine Pflicht, die jedes europäische Land (Preußen z.B. in Paragraph 2 des Emanzipationsgesetzes vom 13. März 1812) den Juden auferlegt hatte, vielmehr als Eigenmächtigkeit aus Täuschungsgründen, zumindest als Eskapade eines eitlen Gecken. Der abgelegte Name nun, der in der Bibel an den Sohn Jakobs und Leas gegeben ist (Gen. 30,18) - woher kannten ihn die Berliner Zuschauer im Jahre 1815 überhaupt? Gewiß nicht aus realem Umgang mit den gerade aufgenommenen jüdischen Mitbürgern, denn von den 1.628 Haushaltsvorständen, die vorschriftsmäßig im Emanzipationsjahr (also drei Jahre vorher) ihren festen Familiennamen gewählt hatten (und dabei in Berlin ausdrücklich auch ihre Vornamen nachbessern konnten $^{46}$ hieß kein einziger so, und es wählte auch kein einziger so. Das nicht genug: Die offensichtlich gut amüsierten Berliner Zuschauer hätten

\footnotetext{
45 Angr. 1929, Nr. 36, S. 6.

46 Bering 1988, S. 60.
} 
auch im ganzen Kurmärkischen Regierungsdepartement - in 63 Ortschaften also, von Angermünde über Potsdam, Frankfurt/O. bis Zossen, alles zusammen: 2700 Haushaltsvorstände - selbst in diesem weiten Areal hätte sie keinen einzigen mit dem Namen "Isaschar" finden können. ${ }^{47}$ Judenfeindliche Phantasie hatte diesen Namen aus biblischem Uraltbestand imaginiert (übrigens kein singulär dastehender Fall) ${ }^{48}$ und mit den gewünschten Assoziationen gefüllt. „Isidor" war (als Gleichklangsname auch zu Isaak) so selten (zweimal auf der Berliner Liste), daß er in dieser Abseitigkeit gut war, das Hochgestochene jenes Morgenländer zu symbolisieren - kein schlechter Griff, denn auf diesen Namen konzentrierten sich dann die namenpolemischen Angriffe ein Jahrhundert, bis er dann schließlich als dichtestes Konzentrat antisemitischer Verunglimpfung Goebbels' Feldzüge gegen den Berliner Polizeivizepräsidenten Bernhard Weiß fast ganz tragen konnte, indem er diesem gut assimilierten preußischen Juden einfach diesen Namen unterschob. ${ }^{49}$

In der Abhandlung „Der Name als Stigma. Antisemitismus im deutschen Alltag" findet sich eine Markierungstabelle, auf der 74 Familiennamen nach der Schwere ihrer antisemitischen Belastung angeordnet sind. $25 \%$ aller Juden trugen einen solchen Namen, freilich $1 \%$ aller deutschbürtigen Deutschen trugen genau dieselben (scheinbar jüdischen) Namen. ${ }^{50}$ Von hinreichender Trennschärfe bei den Namenattacken konnte also nicht die Rede sein. Aber Cohn, Mendel, Aron, Fränkel, Hirsch, Goldstein usw. galten eben aufgrund langer Einübung im 19. Jhdt als jüdisch, ebenso welche mit bestimmten Namenteilen, so die auf -stein, auf -berg oder die auf -eles (Diminutivbildung mit Genitiv) endenden.

Bei den durchaus häufigen "kerndeutschen" Namen der Juden zeigte sich für Antisemiten ein ähnliches Problem wie es ihnen angesichts der lupenrein deutsch sprechenden Juden entgegentrat. Eigentlich war es doch kein richtiges Deutsch, hatten die Antisemiten entgegen der platterdings nicht zu übersehenden Sprachrealität dekretiert und mit Demaskierungen begonnen. Nun kam die zweite Entlarvung der Mimikrynatur „des” Juden auf den Namenebene: Eigentlich hieß er in Wirklichkeit dann ganz

47 Die komplette Liste erschien 1813 als „Beilage zum 40sten Stück des Amtsblatts der Königl. Kurmärkischen Regierung".

48 Hundt-Radowsky nannte in seinem 1819 erschienenen „Judenspiegel" eine Figur, die sich, stark jüdelnd, über die Gewerbefreiheit äußerte: Saul Isaschar (S. 140-142).

Bering 1983.

50 Bering 1988, S. 212-221 und für die Vornamen (mit Isidor als Spitzenwert) S. $238-240$. 
anders: Isaschar statt Isidorus Morgenländer. Wenn es nun für einen solchen Namenswechsel nicht den geringsten Anhaltspunkt gab, ging man einen Schritt weiter: Sollten Mensch und Name übereinstimmen, dann müßte er doch so heißen, eben Isidor statt Bernhard oder wie die Nationalsozialisten 1939 dann auch verwaltungstechnisch vorschrieben: Israel alle jüdischen Männer, Sara alle jüdischen Frauen.

Was geschah also auf dem Felde "Sprache und Antisemitismus" innerhalb des 19. Jhdts, und wofür konnte es in dieser Zeit und später bis zum Ende der Nazi-Herrschaft genutzt werden? Es wurde ein sprachlich fixiertes Vorurteilssystem eingeübt und festgeschrieben, das die Juden nicht mehr als das erscheinen ließ, was sie wirklich waren, sondern in das zwängten, was sie nach Meinung der Antisemiten waren oder: eigentlich sein sollten.

\section{Zersetzende Modernität jüdischen Sprachgebrauchs}

Nachdem nun die Funktion von Namenverfemungen klar ist, finden wir auch bequem auf jenen Weg, der (wie oben angekündigt) als zweiter aus jenem Dilemma der Antisemiten führen sollte, daß doch die Juden im letzten Drittel des 19. Jhdts (und über jeden Zweifel erhaben: im ersten Drittel des 20.) für jedermann hörbar gemeinhin reines Deutsch sprachen und schrieben.

Es entsprang nicht antisemitischer Phantasie, daß Juden in der deutschen Presse eine herausragende Rolle als Verleger, Journalisten, ja überhaupt als Träger der deutschen Kultur spielten. ${ }^{51}$ H. K. Lenz machte sich 1893 (S. 33) in seinem Pamphlet: „Judenliteratur und Literaturjuden" darauf folgenden Reim:

Herr Zwiebeles, Herr Knobeles, Herr Schimpfeles, Herr Lobeles, Herr Schundeles, Herr Pfandeles, Herr Spotteles, Herr Schandeles: Das sind die Meister der Kritik, Die edele Tafelrunde;

51 Die herausragende Stellung der Juden vor allem in der liberalen Presse ist mehrfach betont worden (vgl. z.B. Gay 1989, S. 190-193 u. Suchy 1989 , S. 169). Den Terminus "Zeitungsjude" weist N. Hortzitz (1988, S. 90, 225) schon für die Zeit des Frühantisemitismus nach. Über antisemitische Sprache im Problemfeld Presse vgl. auch Cobet 1973, S. 72-76. Anwürfe wegen der "Mauschelei" in der Presse findet man sozusagen in jedem antisemitischen Pamphlet, vgl. z.B. das Kapitel „Fort mit der Mauschelpresse” in: Der Mauscheljude 1880, S. 27-30; weiter in der antisemitischen Presse: Hammer 1906, Nr. 101, S. 510;1910, Nr. 183, S. 58; 1911, Nr. 214, S. 265 und sehr viel öfter. 
Sie loben jedes neue Werk,

Das riecht nach dern alten Bunde.

Der Kritiker „Schundeles" fördert also auch Minderwertiges. Mag das hier - wie anderswo auch - noch primär inhaltlich gemeint sein, ${ }^{52}$ die Juden werden auch gezielt verklagt, eben den stilistischen Modernismus in den Zeitungen auf dem Gewissen zu haben. Ferdinand Kürnberger, der als erster (1860 und 1876) weitblickend die sprachlichen Modernisierungphänome der Presse untersucht hat, sah nun nicht nur schlechte Seiten an diesen Veränderungen, die eine neue Stilebene heraufführen sollten. Kürnberger prognostizierte: ${ }_{n}$ Schriftsprache wird mehr und mehr heißen: Journalsprache". ${ }^{53}$ Zwar erbringe die progressive Aufnahme sprech- und niedersprachlicher Elemente der Volkssprache eine Mehr an Stärke und Nachdrücklichkeit, die die Presse unbedingt brauche (S. 10),

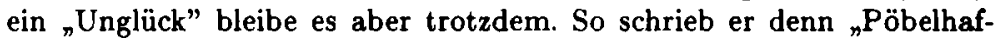
ter Zeitungsstil" über das Kapitel 2, und die zweite Abirrung, die militante Aufrüstung der Presse-Meinungssprache, schilderte er so: „In tjost und buhurt ergraut, sieht man den berühmten Ritter Aaron Mendel für die zollfreie Einfuhr der Halbgarne eine Lanze brechen" und den "Simon Fränkel" für die zollfreie Lumpeneinfuhr sogar „seine Lanze einlegen." 54

Daß zu einer modernen - eben in den deutschen Landen lange hinausgezögerten - demokratischen Öffentlichkeit ein öffentliches Ringen um die Begriffe gehört, galt den Konservativen meist als ein bloßes jüdisches Sprachzerstörungsmanöver, während es modernen Forschern, spätestens seit Brunner, Conze und Kosellecks „Historische Grundbegriffe", ein selbstverständliches Kennzeichen der Sprache seit dem 19. Jhdt ist. Auch hier funktionierte also die Sündenbocktheorie: Jüdische Machenschaften war eben alles, was zur modernen Zeitungssprache gehört. Da nun die Juden wiederum auffällige Exponenten moderner Großstadtkultur waren ${ }^{55}$ und das moderne Zeitungswesen mit diesen Ballungsräumen in genuinem Zusammenhang steht, stimmte scheinbar

52 Änlich nunmehr mit stilistischem Akzent aber ebenso anhand von Namenpolemik: "Der Hammer" in einem Artikel "Eine Schwäche unserer nationalen Presse" (1904, Nr. 39, Febr., S. 50): "Sie loben sich gegenseitig aus dem Drecke heraus. Was Cohn schreibt, wissen Levy und Meyer sofort "geistvoll" zu interpretieren". vv.

53 Kürnberger 1866, S. 25.

54 Kürnberger 1872, S. 4f.

55 Eine oftmals beschriebene Tatsache (vgl. z.B. Rürup 1975, S. 83, 166), die bisher nur von Jacob Toury in Bezug auf die sprachlichen Folgen gewürdigt worden ist (1982, S. 89ff.). 
wieder alles zusammen: Die Juden waren die Profiteure und Arrangeure des modernen Großstadtlebens; dieses galt als Ausgeburt der Zivilisation und Zerstörer deutscher Kultur; also redeten die Juden auch nur in einer „Zivilisationssprache”, der „blutmäßig gebundene Begriffe” unbekannt seien. ${ }^{56}$ Eine tief hinabreichende Tradition und dazu der festgefügte Zusammenhang mit bewußtseinsstrukturierenden Grundvorstellungen (Kultur-Zivilisationsantithese) brachten es dazu, daß 1927 die Forderung des „Der Hammer”, der bekanntesten antisemitische Zeitschrift, vielen plausibel erschien:

Wo der unverbildete deutsch-germanische Mensch spricht, spricht er blutsecht deutsch; wo der Jude "deutsch" spricht, spricht er "jüdischdeutsch". Das Ganze auf kurze Formel gebracht: Entfernen wir aus dem deutschen Zeitungs- und Schriftwesen den überragenden Einfluß der Juden, so haben wir die unmittelbare Heilung aller Schäden der deutschen Zeitungssprache. ${ }^{57}$

Solch absurd anmutende Thesen bekommen weitere systemimmanente Plausibilität, wenn man sich vor Augen hält, daß z.B. die „Fixigkeit” und der Aktualitätszwang der Presse, die den Sprachgebrauch tatsächlich neuen Normen unterwarfen, von eben dieser antisemitischen Zeitschrift schon 1906 (S. 506) aus der typisch jüdischen Behendigkeit, Profitgier und Kaltherzigkeit abgeleitet wurden. Diese Eigenschaften machten eben ein Schreiben ad hoc über alles und jedes überhaupt erst möglich, während doch der Deutsche bei irgendwelchen Katastrophenereignissen erst einmal stocke oder gar ans zeitraubende Helfen denke. Menschen, die mit ihren Einschätzungen auf einer solchen Basis standen, war es dann natürlich nur konsequent, eine ${ }_{n}$ Gesundung des nationalen Leben[s]" von der durchgreifenden Reform des Preß-Wesens zu erhoffen, wo z. Zt. noch „täglich tausend Fälscher und Giftmischer ihre ätzenden

56 Zitate bei Römer 1985, S. 174.

57 Febr. 1927, S. 78, als Kommentar zum 18. Preisausschreiben des Deutschen Sprachvereins: „Die Schäden der deutschen Zeitungssprache, ihre Ursachen und ihre Heilung". 1903 (S. 292f.) hatte er schon - nach vorherigem Lobpreis der "Menschheits-Liebe Wagners" - dekretiert: im Zeitungs-Jargon mache sich die Phrase in so widerlicher Weise breit, , daß der Kampf um eine anschauliche, ehrliche deutsche Sprache nachgerade zur Lebensfrage unseres Volkes geworden ist"; eine ähnliche Äußerung Wilhelm Stapels in seiner national-konservativen Zeitschrift "Deutsches Volkstum" (1921, S. 48f.): „Sie reden unsre Sprache, gebrauchen unsre Begriffe [...] Aber Blut und Seele sind jüdisch und also werden Sprache, Begriffe, Kunstmittel zu einem Ausdruck ihres Vokstums" mit anschließenden Angriffen auf die starke Position der Juden in Kunsthandel, Kritik, Zeitungs- und Buchwesen. Zu solchen Vorstellungswelten paßt dann, daß in den "Alldeutschen Blättern" die "Sprachund die Rasse-Fremden" im "Deutschen Reich" in einem Artikel abgehandelt wurden $(4,1894$, S. $50 \mathrm{f}$.). 
Tropfen in die Gemüter ungestört einflößen" dürften. Ihre konkrete Forderung ging dann 1906 schon dahin, daß nur noch „deutsche Männer deutsche Zeitungen schreiben dürften". 58

Natürlich kann ein moderner Sprachwissenschaftler eben dort nur eine neue stilistische Existenzform der Sprache sehen, ${ }^{59}$ wo die Rechten Zersetzung ausmachten. Der ideologiegeleitete Irrtum der Konservativen hindert nicht, er fordert die Linguisten vielmehr heraus, die Geschichte dieser spezifischen Denunziation endlich zu schreiben.

\section{Antisemitische Metaphorik}

Bei diesem letzten Punkt des Themas "Sprache und Antisemitismus" bedarf es besonders dringlich eines neudurchdachten methodischen Ansatzes. Noch ganz im Glauben an die unbedingt bannende - und damit entschuldigende? - Macht der Sprache befangen, untersuchte man nach dem Kriege alsbald die biologischen Metaphern, die im Sprechen über Juden gehäuft auftraten. ${ }^{60} 1965$ veröffentlichte Alexander Bein Bemerkungen zur Semantik der Judenfrage: „Der jüdische Parasit”. Obwohl er einräumt, daß die biologistisch-organischen Vorstellungen von Sprache bis in die Romantik zurückreichen, schreibt er gleichwohl fest:

Im ausgehenden 19. Jahrhundert und im Beginn des 20. haben drei Entwicklungen sich in ihr vollzogen: die Biologisierung, die Technisierung und die Mythisierung. ${ }^{61}$

So machte man sich dann auch auf und untersuchte die antisemitische Sprache vor allem in eben dieser Zeit. Christoph Cobet z.B. legte 1973

58 Der Hammer 1906, S. 510. Wurde einmal angemahnt, sich die Abhängigkeit spezifischen Geistes und einer spezifischen Sprache nicht zu eng vorzustellen, dann wurden Formulierungen eingefügt, die wiederum eher Angst machten, als daß sie den $\mathrm{HaB}$ gegen Juden abbauen konnten. In den Zeitglossen der Nr. 232 aus dem Jahr 1912 beließ es „Der Hammer” also nicht beim Satz: „Es kann sich jemand sehr wohl der deutschen Sprache bedienen und im Grunde doch recht undeutsch sein." Er fügte an: "Haben wir doch eine Bevölkerungsklasse unter uns, die sich zuweilen der deutschen Sprache geschickter bedient als mancher Deutsche, und dennoch dem deutschen Wesen so fremd und feindselig gegenübersteht, wie nur irgend denkbar" - ohne Zweifel ein ärgerliches Faktum für Menschen mit deklamatorisch überzogenem Selbstwertgefühl.

Vgl. z.B. Kettmann 1981. Im übrigen sind sich alle Sprachwissenschaftler einig: Die Sprache des Rundfunks und der Zeitungen ist heute allemal stilprägender als es die Sprache der Klassik je gewesen sein dürfte.

60 So schon in der ersten ernst zu nehmenden Arbeit von C. Berning 1963, S. $105 \mathrm{ff}$.

61 Bein 1980, S. 123. 
eine Dissertation über den „Wortschatz des Antisemitismus in der Bismarckzeit" vor und wandte sich da vor allem dem ideologie- und wirkungsgeschichtlich zentralen Werk Eugen Dührings zu: „Die Judenfrage als Racen-, Sitten- und Kulturfrage". Er weitet die Fragestellung aber auf die gesamte Bismarckzeit aus und bietet da im lexikalischen Teil „Bezeichnungen für die Juden”. 62 verschiedene führt er an, von denen 15 tatsächlich auf biologische Metaphern zurückgeführt werden können. ${ }^{62}$ Abbau des metapherntragenden Vergleichs zugunsten einer realen Ineinssetzung des ehemals nur Verglichenen schreibt er dann als ein wesentliches Merkmal der biologistischen Sprache des Antisemitismus fest. ${ }^{63}$

Diese Ergebnisse schienen sich den Vorwegannahmen also ganz gut zu fügen. Dennoch, gegen solche vermeintliche Schlüssigkeit gehalten, hätte eine Behauptung doch erstaunend wirken müssen, wie sie George L. Mosse mehrfach in seinem schon 1970 erschienen Buch: "Germans and Jews" vortrug: Praktisch alle sozial-kulturellen Manifestationen, die man der Rassenlehre des späteren 19. Jhdts zuschreibe, seien schon vor dem Aufstieg des Rassismus an der Tagesordnung gewesen. ${ }^{64} \mathrm{Mu}$ stert man die neue sprachwissenschaftliche Forschung, so hat sich diese These bewahrheitet. Nicoline Hortzitz breitet in ihrer Dissertation über den "Frühantisemitismus in Deutschland (1789-1871/72)" erstaunlich umfangreiches Material über biologische Metaphern aus. ${ }^{65}$ Jüngst urteilten Rainer Erb und Werner Bergmann vom Berliner ${ }_{n}$ Zentrum für Antisemitismus-Forschung" in einer umfassenden Darstellung des Emanzipationszeitraumes von 1780 bis 1860 zum Schluß ihres eindringlichen Sprach-Kapitels so:

Vergleicht man die angeführten Beispiele mit der antisemitisihen Semantik des späten 19. Jahrhunderts und weiter bis in die NS-Periode hinein, dann zeigt sich, daß die judenfeindliche Metaphorik in ihren wesentlichen Grundzügen bereits in der Emanzipationsperiode entwickelt war und später zwar Aktualisierungen und eine große quantitstive $\mathrm{Zu}$ nahme, jedoch kaum eine grundsätzliche Veränderung erfuhr. i1989, S. 215).

62 Cobet 1973, S. 215-225. Bluthunde, -igel, -sauger, Krebs, Parasiten (in fünffacher Variation), Schädlinge, Schmarotzer, -insekten, Schwamm, Ungeziefer, Würmer ( $2 \mathrm{x}$ angeführt).

631973 , S. 45f., 243.

64 Mosse 1970, S. 35 u.ö.

65 Sie bietet z.B. in der lexematischen Rubrik mit der Bewertungskonponente "nicht menschengemä $B$ " - aus 34 Quellen systematisch zusammergetragen - 94 Lemmata, von denen 52 aus biologischem Bereich kommen Hortzitz 1988 , S. 177-181). 
Der eigentliche Unterschied liege nur darin, daß es seit der 2. Hälfte des Jahrhunderts zu einer Mythisierung der biologischen Perspektive und zu einer quantitativen Überflutung mit solchen Reden gekommen sei.

Diese neueren Ergebnisse scheinen zunächst einmal richtig. Nimmt man nämlich z.B. eine der verbreitetsten und radikalsten antijüdischen Schriften, von Hundt-Radowskys "Judenspiegel" (1819), so zählt man von S. 61 bis 90 in den drei thematisch durchaus einschlägigen Kapiteln ${ }^{66} 15$ biologisch fundierte Metaphern. Setzt man nun gegen diese Ergebnisse den Befund aus dem eben genannten Werk Eugen Dührings, das den rassistischen Ansatz doch vor allem begründete, so findet man auf den ersten 45 Seiten nur 16, also eher weniger als mehr. ${ }^{67}$ Ehe man nun aus dem allen einfach den SchluB zieht: Alle sprachlichen Mittel sind schon im 19. Jhdt vorgebildet, sogar schon vor der rassistischen Wende; das letzte Drittel des 19. Jhdts und die Nazis brachten außer der Masse nichts Neues, schlage ich eine Vertiefung der Forschungsweisen vor.

Es unterliegt keinem Zweifel, daß die polemisch-pragmatische Kraft der Metapher in ihrem „problem setting” besteht. Das soll heißen: Ist der Staat erst einmal metaphorisch als Schiff definiert, dann ist es leicht, weil konsequent, zu behaupten, daß er auch des (einen) Steuermanns bedarf; dann muß man Untergang fürchten, den unbeherrschbare $\mathrm{Na}$ turgewalten (nicht Menschen) herbeiführen (keiner ist verantwortlich) oder aber Untergang durch den Sabotageakt eines einzigen Verräters an Bord (der allein ist schuld). ${ }^{68}$ Und jetzt das problem setting für Juden

66 "Was sind die Juden?", "Die Juden als Staatsbürger” und „Die Juden als Kaufleute, Geldwechsler und Hausirer!"

67 Es handelt sich thematisch um keineswegs weit von Hundt-Radowsky abgelegene Themen: 1. "Gesellschaftliches Aufkommen der Juden in der neuesten Zeit", 2. "Charakterspiegelung in Religion und Moral".

68 Mechanismen dieser Art sind in letzter Zeit häufig diskutiert und von Stefan G. Stobbe zusammenfassend diskutiert worden. Für die Überlassung seiner noch ungedruckten Dissertation (Marburg 1988) danke ich. Vgl. dort das Kap. I.1.2. „Metapher als Ersatz - Stellvertreter oder Original" mit einschlägigen Zitaten, z.B. "The effect, then, of (metaphorically) calling a man $a$ "wolf" is to evoke the wolf-system of related commonplaces" (Max Black). Oder von Hans Blumenberg: „Der Raum der Metapher ist der Raum der unmöglichen, der fehlgeschlagenen oder noch nicht konsolidierten Begriffsbildung", in unserem Zusammenhang z.B. das Schwanken des nationalsozialistischen Denkens über Juden zwischen Mensch und Tier. Schließlich ein Zitat von Michael Walzer: ${ }_{\text {A }}$ A single vocabulary describes animal bodies and political communities and makes the second appear almost as familiar, as natural, as well organized as the first. So kings become heads and soldiers arms; change is unterstood in terms of growth; disorder is described as a desease; decline as senility". 
als Ungeziefer. Erste durch die Metapher generierte Frage: Wie werden wir mit der Massenhaftigkeit fertig (faktisch imaginierte Realität: die aus dem Osten, eben jenem fast unendlich weiten Sprachraum bei uns „einfallen")? Zweite Frage: Welche Vernichtungsmittel schlagen durch? Dritte: In welcher Weise soll man solche Mittel anwenden? Antwort: heimlich, denn der Kammerjäger agiert nicht coram publico.

Die Gefährlichkeit dieser durch Metaphern eröffneten Assoziationsfelder besteht darin, daß sich - wie in der jüngsten, leider noch unveröffentlichten Dissertation von Stephan G. Stobbe über die völkische Metaphorik bewiesen - die Vorstellung von metaphorischem Assoziationsfeld zu Assoziationsfeld schwingen kann, ohne je zum nicht-metaphorischen Ausgangspunkt zurückzukehren. Es könnte der Unterschied des vorrassistischen und rassistischen 19 . Jhdts nun nicht einfach in der Menge der Metaphern liegen, sondern darin, daß man später immer seltener zum Ausgangspunkt zurückging, die Metaphernwelt also dichter, tiefer ist. Ich gebe ein Beispiel: In seinem abschließenden Kapitel sagt von HundtRadowsky (S. 146):

Am Beßten wäre es jedoch, man reinigte das Land ganz von dern Ungeziefer, und hierzu giebt es gleichfalls zwei Mittel. Entweder die Juden durchaus zu vertilgen oder sie [...] zum Lande hinausjagen.

Mit „Ungeziefer” ist gesetzt 1. der Schritt „reinigen” als Qualifizierung der Abwehrprozedur, 2. "vertilgen" als Art und Weise der Abwehrprozedur. Dieser zweite Schritt wird aber nicht an die Metapher angebunden, sondern es wird 1815 noch zu Jude zurückgegangen und der Metaphorisierungsprozeß damit unterbrochen. Es gilt, eine Methode zu finden, die die Stufen der Beibehaltung von Metaphernperspektiven genau quantifiziert und die lange hinausgezögerten oder gar die vollkommen unterlassenen Rückbezüge dingfest macht. Meine Hypothese ist, daß man im 20. Jhdt viel weiter gespannte Bögen findet, innerhalb derer man das Anfangsobjekt gar nicht mehr in den Blick bekommt. Das durch solche Forschungsmethoden geschärfte Auge sähe vielleicht Erklärungen für ganz eigentümliche Vorgänge: Himmlers berüchtigte Ruhmesrede auf die SS-Leute, die trotz solcher Massenvernichtungsarbeit anständige Leute geblieben seien - sie könnte ein ferner Reflex des problem settings sein. Die Arbeitsweise des Kammerjägers hat bestimmte soziale Folgen: Sein Beruf zählt zu den nicht-ehrbaren. Himmlers Rede könnte auch ferner Nachklang auf solcherart Folgen sein, die die Ausgangsmetapher für die Täter nach sich zieht.

Systematische Erforschung des problem-setting und genaue Vermessung der metaphorischen Bögen ist mein erster Vorschlag. Und ein zweiter: Die problem-setting-Kraft der Metapher wächst dramatisch, wenn es andere 
Metaphernsysteme gibt, die Anschlußmöglichkeiten bieten. Erst muß der Staat konkret als biologistisch gefaßter "Organismus" gesehen werden, daß die Gesamtbedrohung durch „Befall" plausibel wird. Nimmt man nun z.B. die Jahrhundertmitte, so dominiert in Preußen die Vorstellung vom "christlichen Staat". Liest man die einschlägigen Quellen: Stahls Staatslehre, den Briefwechsel Friedrich Wilhelm IV. mit den Gebrüdern Gerlach und mit Bunsen, so findet man in der Staatslehre eine sehr sparsame Verwendung biologischer Metaphern. Am Ende des 19. Jhdts aber und dann allemal in der Weimarer Republik bei den rechten Kräften: da dominiert der völkisch-organisch gedachte Staat - wie allgemein bekannt und von Stobbe an einer umfassenden Untersuchung über Wilhelm Stapel und seine Zeitschrift "Deutsches Volkstum" detailliert bewiesen ist. Jetzt passen die Metaphernsysteme von Ungeziefer und befallenem Organ zusammen.

Natürlich wird keiner mehr glauben, unausweichlich sei die Vernichtung der Juden, wenn man sie ins Metaphernsystem "Ungeziefer" gezwungen hat innerhalb eines Staates, der sich vornehmlich als natur-wüchsiges, organisches Gebilde sieht. Ebensowenig wird aber jemand abstreiten, daB menschenunwürdige Behandlung bei einer derart systematischen Herausdrängung aus sonst für Menschen gültigen Sprachsystemen prädisponiert. Was nämlich sonst als Grauen aus einer planen Alltagsperspektive unübersehbar herausstünde, das wird mittels dieser Metaphernsysteme zunächst einmal sprachlich als gängige Normalität eingeebnet und wird so erheblich unauffälliger - beileibe nicht unsichtbar.

Von dem zuletzt geschilderten Falle aus könnte man den Extrakt des Vortrages so darbieten: Es scheint klar, daß die sprachlichen Wurzeln, besser: mehr als nur die Wurzeln des Komplexes nsprache und Antisemitismus" im 19. Jhdt liegen. Daß sie sich aber im folgenden so dramatisch auswuchsen, läßt sich vielleicht nicht so sehr aus ihnen selbst erklären, wie daraus, daß diese Wurzeln im 20. Jhdt mit ganz anderen Systemen interagieren konnten.

\section{Literatur}

190 gepfefferte Jüdische Witze (o.J., um 1900). Weißensee bei Berlin.

Althaus, Hans Peter (1965/68): Die jiddische Sprache. Eine Einführung. 2 Teile. In: Germania Judaica. NF 14. 4. Jg. Heft 4, S. 1-23; NF 23. 7. Jg. Heft 1, S. 1-24.

Althaus, Hans Peter (1968): Die Erforschung der Jiddischen Sprache. In: Zeitschr. für Mundartforschung. Beihefte NF. Nr. 5, S. 224-263. 
Althaus, Hans Peter (1981): Soziolekt und Fremdsprache. Das Jiddische als Stilmittel in der deutschen Literatur. In: $\mathrm{ZfdPh} 100$. Sonderheft Jiddisch, S. 212-232.

Althaus, Hans Peter (1986): Ansichten vom Jiddischen. Urteile und Vorurteile deutschsprachiger Schriftsteller des 20. Jahrhunderts. In: Röll, Walter/Bayerndörfer, Hans-Peter: Auseinandersetzungen um jiddische Sprache und Literatur. Jüdische Komponenten in der deutschen Literatur. Die Assimilationskontroverse. Tübingen, S. 63-71.

Bartels, Adolf (1906): Heinrich Heine. Auch ein Denkmal. Dresden/Leipzig.

Bartels, Adolf (1915): Nationale oder universale Literaturwissenschaft. Eine Kampfschrift gegen Hanns Martin Elster und Richard M. Meyer. München.

Bein, Alex (1965): Der jüdische Parasit. In: Viertel-J.-Hefte f. Zeitgesch. 13, S. 121-149.

Bein, Alex (1980): Die Judenfrage - Biographie eines Weltproblems. 2 Bde. Stuttgart.

Bering, Dietz (1983): Der Kampf um den Namen Isidor. Polizeivizepräsident Bernhard Weiß gegen Gauleiter Joвeph Goebbels. In: BZN. NF 18, S. 121-153.

Bering, Dietz $\left({ }^{2} 1988\right)$ : Der Name als Stigma. Antisemitismus im deutschen Alitag 1912-1933. Stuttgart.

Berning, Cornelia (1963): Die Sprache des Nationalsozialismus. In: Zs. f. dte Wortforschung 19, S. 94-112.

Bernsmeier, Helmut (1980): Der Allgemeine Deutsche Sprachverein in der Zeit von 1912 bis 1932 . In: Muttersprache 90, S. 117-140.

Best, Otto F. (1973): Mameloschen. Jiddisch - Eine Sprache und ihre Literatur. Frankfurt/M.

Birnbaum, Nathan (1910): Der „Jargon”. In: ders.: Ausgewählte Schriften zur jüdischen Frage. Bd. 2. Czernowitz, S. 46-51.

Birnbaum, Nathan (1910): Die Sprache des jüdischen Volkes. In: ders.: Ausgewählte Schriften zur jüdischen Frage. Bd. 1. Czernowitz, S. 308-325.

Birnbaum, Salomo A. (1974): Die jiddische Sprache. Ein kurzer Überblick und Texte aus acht Jahrhunderten. Hamburg. 
Bischoff, E. $\left({ }^{3} 1901\right)$ : Jüdisch-Deutscher Dolmetscher. Ein praktisches JargonWörterbuch. Leipzig.

Cobet, Christoph (1973): Der Wortschatz des Antisemitismus in der Bismarckzeit. München (=Münchner Germanistische Beiträge 11).

Der Mauscheljude $\left({ }^{4} 1880\right)$, von einem deutschen Advokaten. Ein Volksbüchlein für deutsche Christen allen Bekenntnisse. Paderborn.

Dühring, Eugen (1881): Die Judenfrage als Racen-, Sitten- und Culturfrage. Mit einer weltgeschichtlichen Antwort. Karlsruhe/Leipzig.

Erb, Rainer/Bergmann, Werner (1989): Die Nachtseite der Judenemanzipation. Der Widerstand gegen die Integration der Juden in Deutschland 1780-1860. Berlin (=Antisemitismus und jüdische Geschichte 1).

Frank, Horst Joachim (1976): Dichtung, Sprache, Menschenbildung. Geschichte des Deutschunterrichts von den Anfängen bis 1945. 2 Bde. München.

Freimark, Peter (1980): Sprachverhalten und Assimilation. Die Situation der Juden in Nordwestdeutschland in der 1. Hälfte des 19. Jahrhundert. In: Saeculum 31, S. 240-261.

Frey, Thomas (d.i. Fritsch, Theodor) (1887): Antisemiten-Katechismus. Eine Zusammenstellung des wichtigsten Materials zum Verständniß der Judenfrage. Leipzig.

Gay, Peter (1989): Der berlinisch-jüdische Geist. Zweifel an einer Legende. In: ders.: Freud, Juden und andere Deutsche. Herren und Opfer in der modernen Kultur. München, S. 189-206.

Gelber, Mark H. (1986): Das Judendeutsch in der deutschen Literatur. Einige Beispiele von den frühesten Lexika bis Gustav Freytag und Thomas Mann. In: Moses, Stéphane/Schöne, Albrecht: Juden in der deutschen Literatur. Frankfurt/M., S. 162-178.

Gessinger, Joachim (1980): Sprache und Bürgertum. Zur Sozialgeschichte sprachlicher Verkehrsformen im Deutschland des 18. Jahrhunderts. Stuttgart.

Gilman, Sander L. (1980): Moses Mendelssohn und die Entwicklung einer deutsch-jüdischen Identität. In: ZfdPh 99, S. 506-520.

Goethe, Johann Wolfgang ( $\left.{ }^{4} 1961\right)$ : Werke. Hamburger Ausgabe. Bd. 14 .

Goldziher, Ignaz (1978): Tagebuch. Hrsg. von A. Scheiber. Leiden. 
Hauser, Otto (1933): Die Juden und Halbjuden der deutschen Literatur. Danzig/Leipzig.

Holeczek, Heinz (1981): Die Judenemanzipation in Preußen. In: Martin, B./Schulin, H. (Hrsg.), S. 131-160.

Hortzitz, Nicoline (1988): 'Früh-Antisemitismus' in Deutschland (1789-1871/ 72). Strukturelle Untersuchungen zu Wortschatz, Text und Argumentation. Tübingen (=Germanistische Linguistik 83 ).

Hundt-Radowsky, Hartwig v. (1819): Judenspiegel. Ein Schand- und Sittengemälde alter und neuer Zeit. Würzburg.

Jakobson, R. (1945): The Beginnings of National-Self-Determination in Europe. In: Fishman, J.A. (Hrsg.) (1968): Readings in Sociology of Language. The Hague/Paris, S. 585-597.

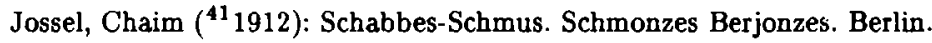

Kettmann, Gerhard (1981): Die Existenzformen der deutschen Sprache im 19. Jahrhundert - ihre Entwicklung und ihr Verhältnis zueinander unter den Bedingungen der industriellen Revolution. In: Schildt, J. (Hrsg.): Auswirkungen der industriellen Revolution auf die deutsche Sprachentwicklung im 19. Jahrhundert. Berlin, S. 34-97.

Kiefer, Ulrike (1985): Das Jiddische in Beziehung zum Mittelhochdeutschen. In: Besch, W./u.a. (Hrsg.): Sprachgeschichte. Ein Handbuch zur Geschichte der deutschen Sprache. Bd. 2, S. 1201-1210.

Kocka, Jürgen (1988): Bürgertum und bürgerliche Gesellschaft im 19. Jahrhundert. Europäische Entwicklungen und deutsche Eigenart. In: ders. (Hrsg.): Bürgertum im 19. Jahrhundert. Deutschland im europäischen Vergleich. Bd. 1. München, S. 11-78.

Kürnberger, Ferdinand (1967): Feuilletons. Ausgew. und eingel. von K. Riha. Frankfurt/M. (darin: Sprache und Zeitungen, 1866; Die Blumen des Zeitungsstils, 1872).

Lenz, H.K. (1895): Jüdische Eindringlinge im Wörter- und Zitatenschatz der deutschen Sprache. Allen Sprachreinigern gewidmet. Münster i. W.

Lowenstein, Steven M. (1976): The Pace of Modernisation of German Jewry in the Nineteenth Century. In: Leo Baeck Institute Yearbook 21, S. 41-56.

Martin, Bernd/Schulin, Ernst (Hrsg.) (1981): Die Juden als Minderheit in der Geschichte. München (=dtv 1745). 
Maurer, Trude (1986): Ostjuden in Deutschland. Hamburg.

Moses, Stéphane/Schöne, Albrecht (Hrsg.) (1985): Juden in der deutschen Literatur. Frankfurt/a. M.

Neubauer, Hans-Joachim (1987): Auf Begehr: Unser Verkehr. Über eine judenfeindliche Theaterposse im Jahre 1815. In: Erb, Rainer/Schmidt, Michael: Antisemitismus und jüdische Geschichte. Berlin (=Festschrift für Herbert A. Strauss), S. 313-328.

Neubauer, Hans-Joachim (1988): Karl Borromäus Alexander Sessas Posse "Unser Verkehr" und ihre Nachfolgestücke. Eine Vergleichende Untersuchung. Unveröffentl. Magister-Arbeit. FU Berlin.

Prawer, Siegbert S. (1986): „Das verfluchte Gemauschel”. Jiddische Dichtung im Kampf der Sprachen. In: Kontroversen. Alte und neue. Bd. 1. Tübingen (=Internationaler Germanisten-Kongreß Göttingen), S. 96-110.

Rée, Anton (1844): Die Sprachverhältnisse der heutigen Juden, im Interesse der Gegenwart und mit besonderer Rücksicht auf Volkserziehung. Hamburg.

Römer, Ruth (1985): Sprachwissenschaft und Rassenideologie in Deutschland. München.

Rürup, Reinhard (1975): Emanzipation und Antisemitismus. Studien zur „Judenfrage” der bürgerlicher Gesellschaft. Göttingen.

Sessa, Karl Borrhomäus Alexander (o.J.): Unser Verkehr. Eine Posse in einem Aufzuge. Leipzig.

Siebert-Ott, Gesa (1990): Kulturverlust - Sprachverlust - Identitätsverlust. Gedanken zu Neuorientierung einer Pädagogik als Ethnopädagogik oder interkultureller Pädagogik. In: Diskussion Deutsch. H. 114, S. 434-448.

Stapel, Wilhelm (1928): Über das seelische Problem der Symbiose des deutschen und des jüdischen Volkes. Hamburg.

Stobbe, Stefan G. (1989): Die Bildersprache des deutschen Volksturns Eine Studie zur national-völkischen Metaphorik. Diss. Marburg. (unveröffentl.).

Strauss, Herbert A. (1985): Akkulturation als Schicksal. Einleitende Bemerkungen zum Verhältnis von Juden und Umwelt. In: Ders./Hoffmann, Christhard (Hrsg.): Juden und Judentum in der Literatur. München. 
Stußlieb, Ernst (1982): Der Aufgeblasene Talmudlöwe. Ergötzliche Gespräche und lehrreiche Gespräche des Herrn Schochet Isidor Eisenstein mit seinem Sohne Moritz. Würzburg.

Suchy, Barbara (1989): Die jüdische Presse im Kaiserreich und in der Weimarer Republik. In: Schoeps, J.H. (Hrsg.): Juden als Träger bürgerlicher Kultur in Deutschland. Stuttgart/Bonn, S. 311-328.

Toury, Jacob (1977): Der Eintritt der Juden ins deutsche Bürgertum. In: Liebeschütz, Hans/Paucker, Arnold (Hrsg.): Das Judentum in der Deutschen Umwelt 1800-1850. Tübingen (= Schriftenreihe wissenschaftlicher Abhandlungen des Leo Baeck Instituts 35), S. 139-242.

Toury, Jacob (1982): Die Sprache als Problem der jüdischen Einordnung im Deutschen Kulturraum. In: Jahrbuch des Instituts für deutsche Geschichte. Beiheft 4, S. 75-96.

Volkov, Shulamit (1990): Deutsche und Juden im Zeitalter der Emanzipation. Überlegungen zu historischen Erfahrungen. In: NZZ v. 7.9. Nr. 206.

Wagner, Richard (1850): Das Judenthum in der Musik. In: Gesammelte Schriften und Dichtungen. Bd. 5. Leipzig, S. 66-85.

Weissberg, Josef (1988): Jiddisch. Eine Einführung. Bern u.a. (=Germanistische Lehrbuchsammlung 27).

Zmarzlik, Hans-Günter (1981): Antisemitismus im Deutschen Kaiserreich 1871-1918. In: Martin, B./Schulin, E. (Hrsg.), S. 249-270. 